\title{
Investigation of the Unsteady Flow Generated by an Axial Fan: Experimental Testing and Simulations
}

\author{
R. S. Amano \\ Department of Mechanical Engineering, College of Engineering and Applied Science, University of Wisconsin-Milwaukee, \\ Milwaukee, WI 53201-0784, USA \\ Email:amano@uwm.edu
}

\section{E. K. Lee}

Department of Mechanical Engineering, College of Engineering and Applied Science, University of Wisconsin-Milwaukee, Milwaukee, WI 53201-0784, USA

Email:englee@uwm.edu

\section{C. $\mathbf{X u}$}

Department of Mechanical Engineering, College of Engineering and Applied Science, University of Wisconsin-Milwaukee, Milwaukee, WI 53201-0784, USA

Email: cxu@uwm.edu

Jianhui Xie

Department of Mechanical Engineering, College of Engineering and Applied Science, University of Wisconsin-Milwaukee, Milwaukee, WI 53201-0784, USA

Email:xie@uwm.edu

Received 29 September 2003

The unsteady flow measurement of a large axial fan with diameter $1.829 \mathrm{~m}(6 \mathrm{ft})$ has been carried out. The complex flow field generated by the fan is investigated through experimental testing and CFD/FEA simulation. The results presented in this paper can be divided into three parts. The first part consists of the experimental description of the test facility, velocity measurement, flow-field visualization, and stress/strain analysis of the fan blades. The second part consists of the CFD simulation of the flow field. Simulation is carried out to analyze the flow pattern with and without a radiator attached to the fan casing. The results presented in this paper can be used as a reference for axial fan performance improvement in the future.

Keywords and phrases: axial fan, pressure measurement, CFD/FEA simulation, unsteady flow.

\section{INTRODUCTION}

Axial fans are used in various areas of industry such as mine ventilation, air-conditioning systems, heat exchangers, and so forth. They are used to discharge air in the area to be ventilated or force air to move into heat exchangers. Detailed experimental research in the axial fans has been one of the major concerns of HVAC industries. This is because significant improvement in the axial fan performance can be achieved if the aerodynamic and vibration losses are reduced within the fan. The aerodynamics of turbo machines has been extensively investigated for many years. Abramovich [1] studied the air distribution in a dead-end channel by using an axial

This is an open access article distributed under the Creative Commons Attribution License, which permits unrestricted use, distribution, and reproduction in any medium, provided the original work is properly cited. fan. The study showed that in a duct system, very high velocities resulted at the discharge section but relatively low velocities occurred throughout the body of the flow path. Mutama and Hall [2] studied the pressure distributions of a jet fan traveling from one wall along the axis of a tunnel in order to optimize the location of the jet fan. Huyer et al. [3] studied the unsteady aerodynamics of a wind turbine associated with a change in yaw angle through steady pressure measurements. In addition to that, Kaupert and Staubli [4] extensively investigated the unsteady pressure field within a centrifugal pump impeller. Their measurements consist of the influence of varying the volume flux on the pressure field due to the influence of the pump volute and the unsteady field study of the transient hysteresis in the pump characteristics. However, unsteady measurements related to the axial fan are still limited in open literature. In view of that, this paper presents the details of an axial fan testing. The 

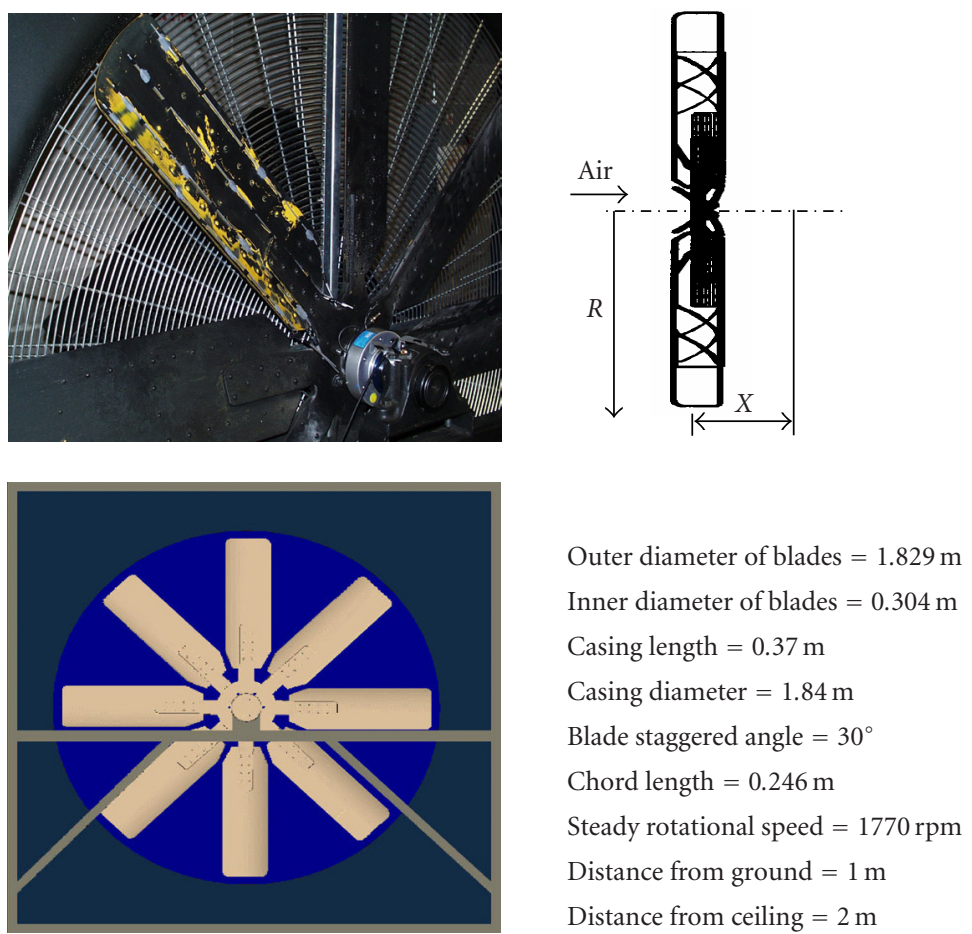

Figure 1: Dimensions of the axial fan and its sideview.

results include an experimental description of the test facility, velocity measurement, flow-field visualization, pressure measurement, and stress/strain analysis of the fan blades, FEA modeling of the inertia and pressure forces on the blade surface, and the CFD simulation of the flow field.

\section{EXPERIMENTAL TESTING AND MEASUREMENT}

An eight-blade industrial axial fan designed for ventilation and oil industries, as shown in Figure 1, is studied in this paper. The airflow surrounding the fan blade is extremely complicated since the flow is mainly unsteady, three-dimensional, and turbulent in nature. In this section, attempts have been made to measure the airflow velocity as a function of the radial distance. The results include the velocity profile for the axial fan with and without a radiator attached to the metal casing. The effect of a radiator on the flow field will be discussed. Flow visualization technique has also been performed to visualize the flow behavior on a typical fan blade.

\subsection{Velocity profile}

The air discharge velocity is measured by a handheld anemometer along the surface of a fan blade. Once the discharge velocity profile is known, the dynamic pressure can easily be determined using Bernoulli's equation. The air velocity is measured at an equally spaced distance along the surface of the fan blade. The result shown in Figure 2 is the average velocity at selected radial locations on the fan blade. The corresponding dynamic pressure is shown in Figure 3. It is expected that the velocity of air would increase expo-

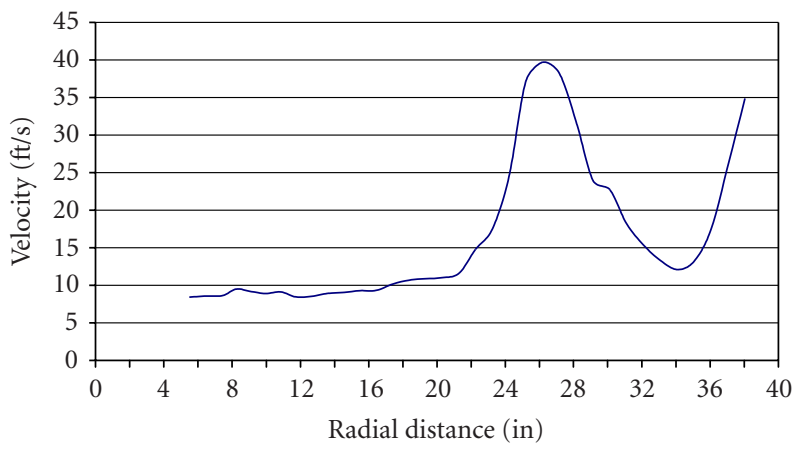

FIGURE 2: Fan discharge velocity profile as a function of radial distance along the fan blade.

nentially from the hub of the blade to the tip. However, the measured results show that the real situation is very much different than what is expected. Figure 2 shows that the velocity increases slowly close to the hub of the blade before a sharp increase is observed at a distance of $0.67 \mathrm{~m}$, after which the velocity decreases and increases abruptly again. This phenomenon will be explained later when the flow visualization technique is performed.

\subsection{Flow visualization}

The "tuft method" is used in this study for flow visualization. The tufts are made of yarn and cut to a length of 2 inches so that drag forces would dominate over centrifugal forces. The yarn could not be much longer than 2 inches since the 


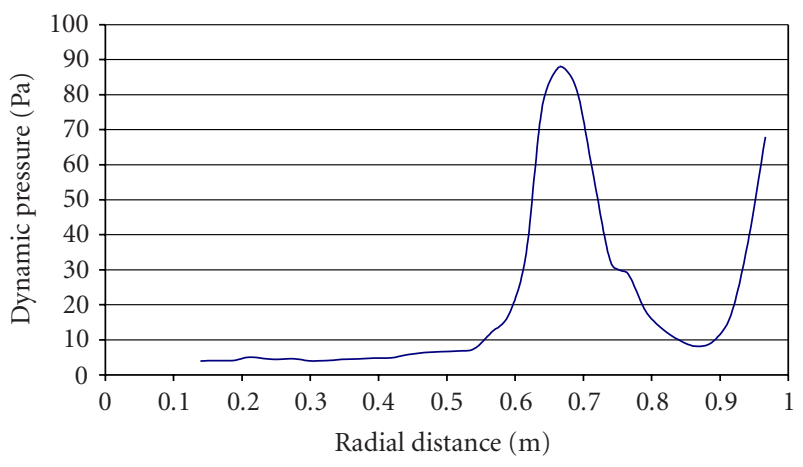

Figure 3: Dynamic pressure as a function of radial distance along the fan blade.

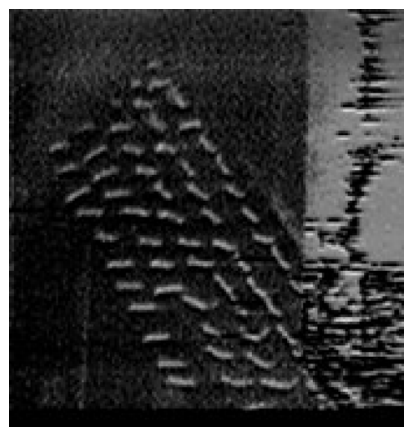

FIGURE 4: A still frame recorded by the high-speed camera for flow visualization.

pieces would begin to cross over into other velocity fields and would no longer represent a straight vector. The motion of the yarns is captured by a high-speed video camera. A single frame is captured from the recording footage and is shown in Figure 4, from which all the tuft angles are measured graphically. From this graphical data, a computer image is constructed to represent the flow over the blade, which is illustrated in Figure 5. Discharge velocity profile and flow visualization correlations are shown in Figure 6.

There is a strong correlation between the flow visualization and discharge velocity profile. It is assumed that the discharge velocity is dominated by the velocity component tangential to the fan blade rather than the velocity component along the blade. For tufts closer to the hub, the velocity is small, but the velocity increases to the maximum at approximately $0.67 \mathrm{~m}$ from the hub. The flow then decreases near the tip of the blade and then increases near the metal casing. This indicates that the flow pattern is highly chaotic due to tip vortices and flow interactions between the metal casing and fan blades.

\subsection{Stress/strain measurement on a fan blade}

Forces are generated as the fan blades rotate, thus causing stress and strain on the blades. In this case, a radiator is attached to the fan casing in order to compare the magnitude of stress/strain generated. Ten strain gages are placed at selected locations over the blade of the fan as illustrated in Figure 7. The results of the experimental measurement are

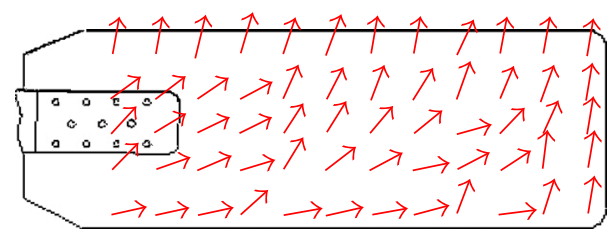

Figure 5: Computer model for flow visualization.
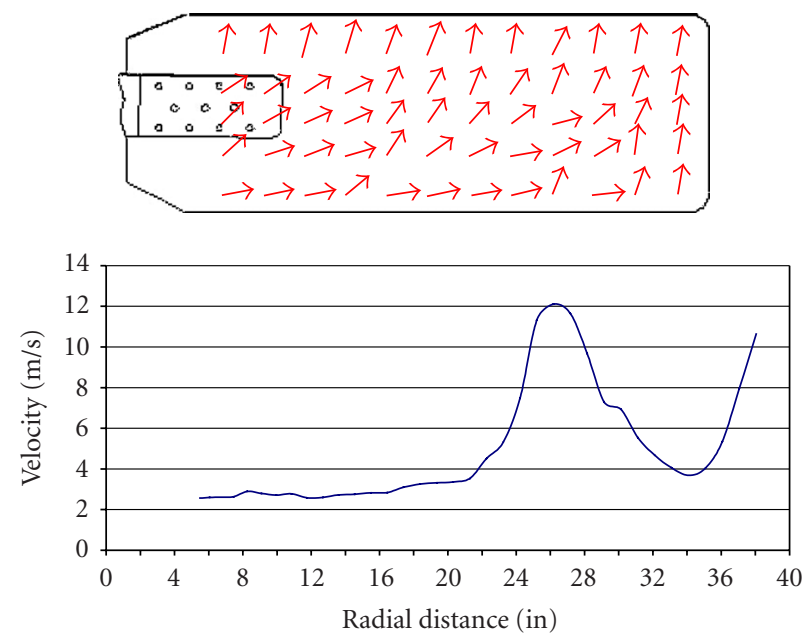

FIGURE 6: Discharge velocity profile and flow visualization correlation.

compared with the results from the finite element analysis as shown in Table 1, and strain gage results comparison (with radiator) are listed in Table 2 . The strain decreases slightly as the position is moved farther away from the center of the fan in the radial direction. Thus the strain, and the stress, was larger at the inner radius of blade and less at the outer radius. The maximum stress is at gage locations no. 2 and no. 3, both with and without radiator. This is the position near the thicker support, where the blade is riveted to the hub of the fan. This abrupt change in thickness increases the stress concentration. Therefore, this would be the first location in which microcavities and microtearing would begin. It is, therefore, the first location to expect blade failure. It is also interesting to note that the strain is not perfectly symmetrical across the blade. Gages no. 5 and no. 7, for example, are located in approximately in the center radius of the fan and are symmetrically positioned. The location of gage no. 5 , on the trailing edge, corresponded to $8.69 \mathrm{kpsi}$ without radiator, and gage no. 7 , on the leading edge, corresponded to $7.75 \mathrm{kpsi}$ without radiator. This is the same general trend of all three sets of gages. Thus, the strain and the stress are higher at the trailing edge than at the leading edge as the fan rotates.

The effects of the radiator resulted in a fairly significant increase in the stress and strain. The average stress over the surface of the fan blade was $7.88 \mathrm{kpsi}$ without the radiator. The addition of the radiator increased the stress over the fan blade surface to $8.81 \mathrm{kpsi}$. This is an average stress increase of $11.8 \%$. The stress increased at all locations of the fan blade 
TABLE 1: Comparison of maximum stresses present in a fan blade at steady state.

\begin{tabular}{|c|c|c|c|c|}
\hline Strain gage location & FEA results $(\mathrm{MPa})$ & $\begin{array}{l}\text { Strain gage results (MPa) } \\
\text { (without radiator) }\end{array}$ & $\begin{array}{l}\text { Strain gage results (MPa) } \\
\text { (with radiator) }\end{array}$ & $\begin{array}{c}\text { Change } \\
\text { due to radiator }(\%)\end{array}$ \\
\hline 1 & 41 & 61 & 70 & $+15.21 \%$ \\
\hline 2 & 52 & 76 & 87 & $+14.21 \%$ \\
\hline 3 & 29 & 74 & 91 & $+22.14 \%$ \\
\hline 4 & 19 & 58 & 66 & $+13.82 \%$ \\
\hline 5 & 36 & 60 & 37 & $-38.20 \%$ \\
\hline 6 & 21 & 55 & 70 & $+27.99 \%$ \\
\hline 7 & 22 & 53 & 66 & $+23.22 \%$ \\
\hline 8 & 29 & 39 & 37 & $-4.78 \%$ \\
\hline 9 & 19 & 34 & 39 & $+18.28 \%$ \\
\hline 10 & 23 & 34 & 45 & $+31.67 \%$ \\
\hline
\end{tabular}

TABLE 2: Strain gage results comparison (with radiator).

\begin{tabular}{ccc}
\hline Blade location & $\begin{array}{l}\text { Strain gage results } \\
\text { (front of fan) }(\mathrm{MPa})\end{array}$ & $\begin{array}{c}\text { Strain gage results } \\
\text { (behind fan) }(\mathrm{MPa})\end{array}$ \\
\hline 1 & 70 & 84 \\
2 & 87 & 106 \\
3 & 91 & 108 \\
4 & 66 & 82 \\
5 & 37 & 82 \\
6 & 70 & 77 \\
7 & 66 & 76 \\
8 & 37 & - \\
9 & 397 & 47 \\
10 & 45 & 58 \\
\hline
\end{tabular}

with the addition of the radiator, except at strain gages no. 5 and no. 8, where the stress slightly decreased. Finding the strain and stress on the back of the fan blade validated the results that were obtained on the front of the fan blade. The stresses were somewhat higher, however, the stress and strain decreased as the position was moved farther away from the hub in the radial direction. The maximum stresses were at the same locations as on the front (no. 2 and no. 3 ).

Comparing the stress results from the finite element analysis with the data obtained from the strain gage experimental testing (with and without radiator), a number of important conclusions can be made. The stresses at the 10 locations were obtained from the complex finite element model (Figures 1-14) by analyzing the model after it had been solved at the strain gauge location coordinates. Table 1 presents the maximum von Mises stress at each of the 10 locations as shown in Figure 7. Note that the actual stress at any location fluctuates very rapidly, even under steady-state conditions, which is possibly due to air pressure changes and vibration.

Referring to Table 1, it can be seen that there is a difference between the finite element stresses and those obtained in the two strain gage experiments. The difference between the finite element and the strain gage results ranges from $26 \%$ to $67 \%$. The primary reason for this large difference is that the finite element analysis does not consider the effects of vibration in producing fluctuating stresses in the fan blade.

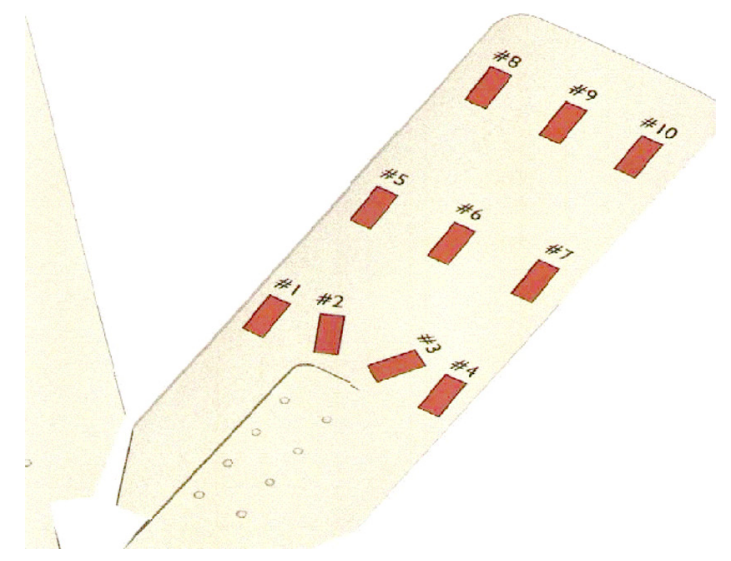

FIgURE 7: Strain gage locations on the fan blade.

Even though there are large discrepancies between the theoretical FEA and experimental results, the finite model is still very useful since its results follow the same trends present in both experimental strain gauge analyses. Differences in calculated stresses between these two analyses range from $2.4 \%$ to $28.3 \%$ without radiator. With the radiator, the experimental results differ by $5 \%$ to $31 \%$. The addition of the radiator increased the stress over the surface of the blade at all locations, except strain gages no. 5 and no. 8. On average, the addition of the radiator resulted in an increase of $11.8 \%$.

\section{COMPUTATIONAL FLUID DYNAMICS SIMULATION}

A comprehensive three-dimensional CFD simulation is carried out for a $1.829 \mathrm{~m}(6 \mathrm{ft})$ diameter commercial axial fan with rotation speed of $1014 \mathrm{rpm}$. The use of FLUENT has made it possible to simulate complex moving geometries found in rotating machinery such as fans, pumps, compressors, and so forth. Simulations can be performed for steadystate conditions using an implicit rotating reference frame for the blade. The computer model generated for the axial fan using PRO-E is shown in Figure 8. In this CFD simulation study, the flow pattern is investigated for an axial fan with and without a radiator attached to the casing.

A single blade is used as the calculation domain in the CFD simulation as illustrated in Figure 9. Figure 10 shows 


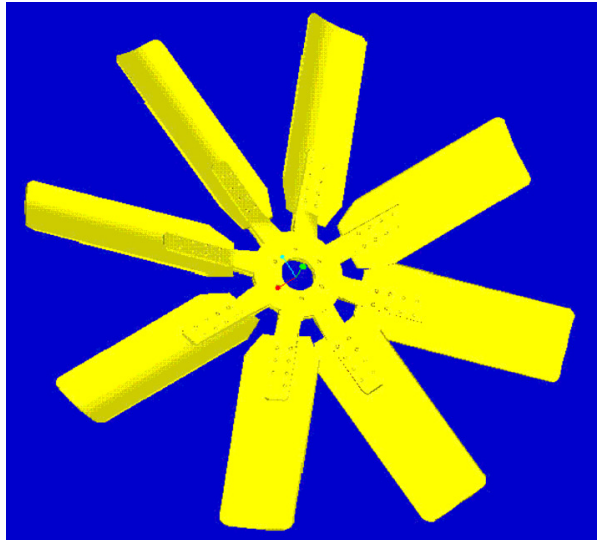

Figure 8: CAD model of the axial fan.

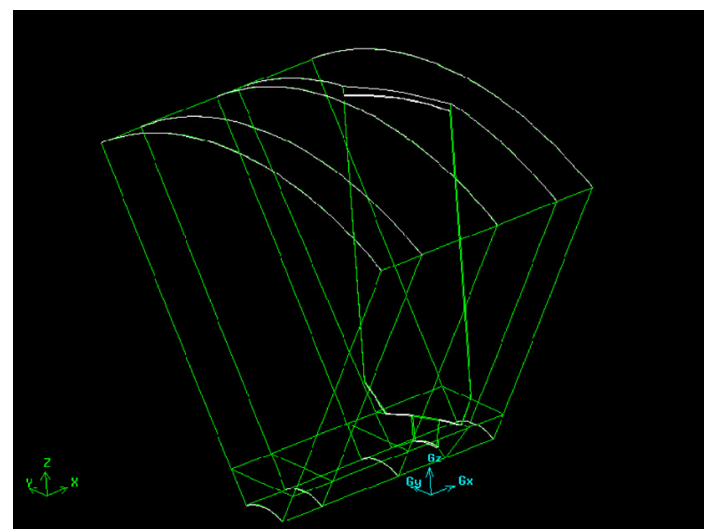

FIgURE 9: Calculation domain used in FLUENT simulation.

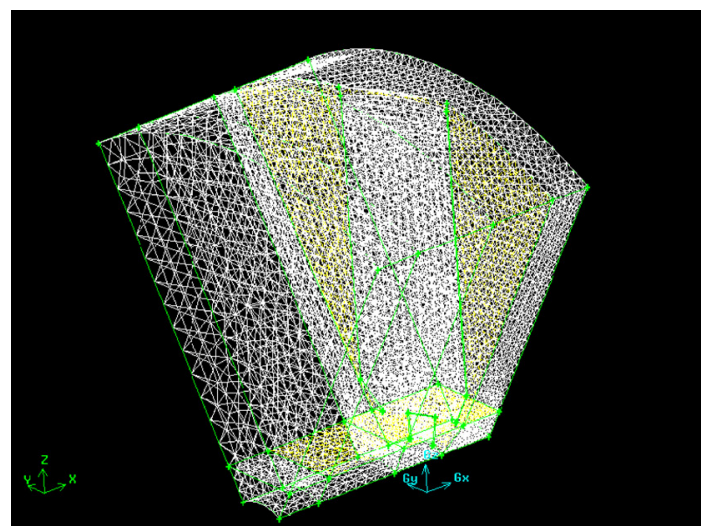

FIGURE 10: Mesh generation for a single blade used in FLUENT simulation.

the mesh generation of the blade using unstructured grid, which consists of approximately 80000 tetrahedral cells and 16000 nodes.

\subsection{Axial fan without radiator}

In this section, the pressure and velocity distribution on the blades of an axial fan without a radiator attached to the metal

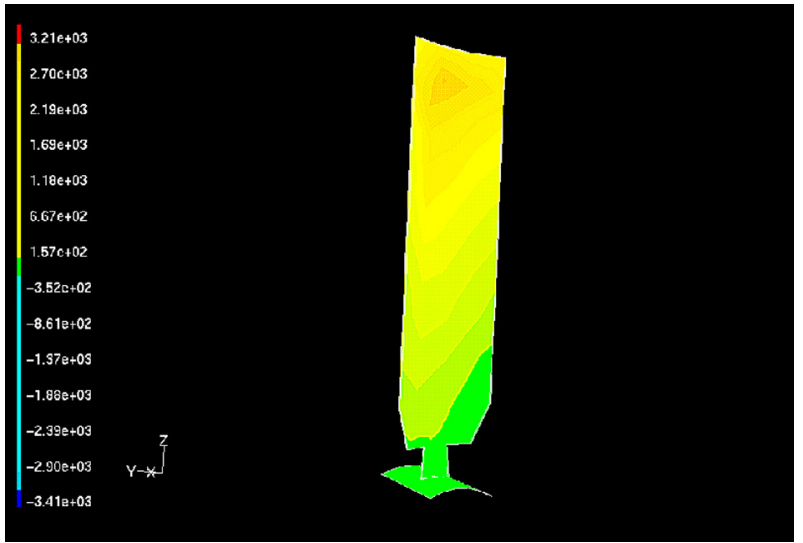

FIgURE 11: Static pressure distribution on pressure side of a fan blade without radiator (unit in Pascal).

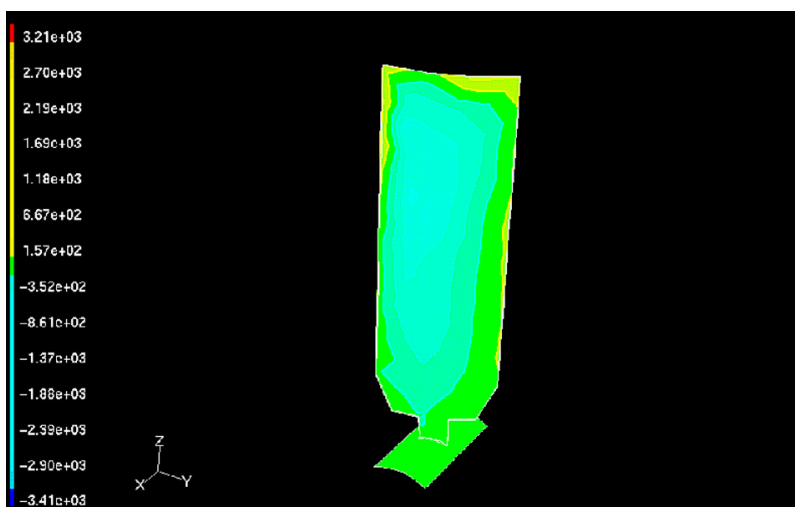

FIGURE 12: Static pressure distribution on suction side of a fan blade without radiator (unit in Pascal).

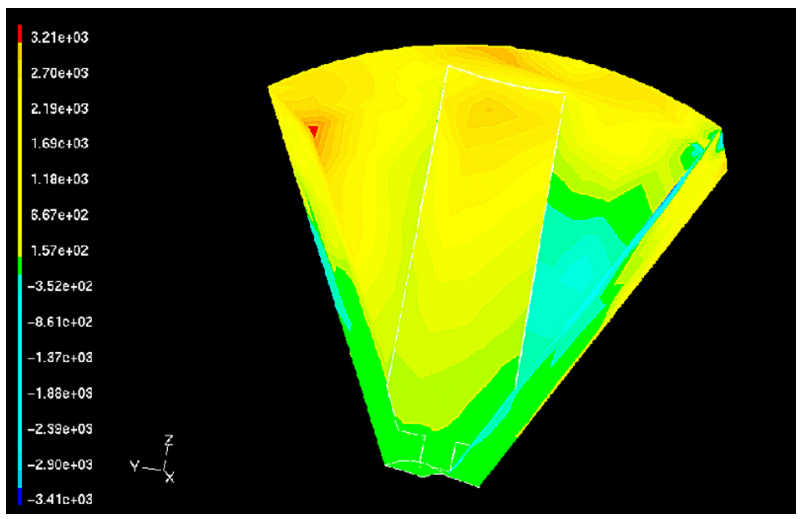

Figure 13: Static pressure on the pressure side and top face of the domain without radiator (unit in Pascal).

casing is simulated. Figure 11 shows the static pressure on the pressure side of the fan; while Figure 12 shows that on the suction side. It can be seen that certain part on the blade has pressure lower than the atmospheric pressure. The maximum pressure occurs at the center of the blade close to the hub and also at the tip of the blade. Shown in Figure 13 is the static pressure on the pressure side of the calculation domain. 


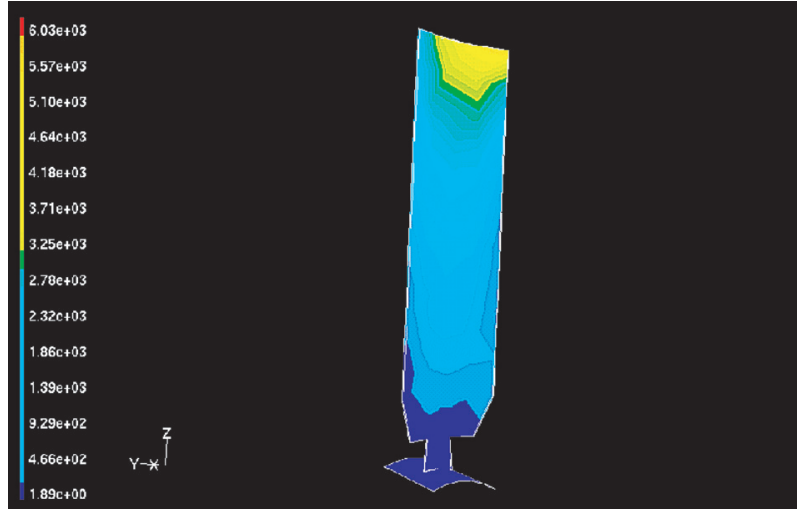

FIgURe 14: Dynamic pressure on the pressure side without radiator (unit in Pascal).

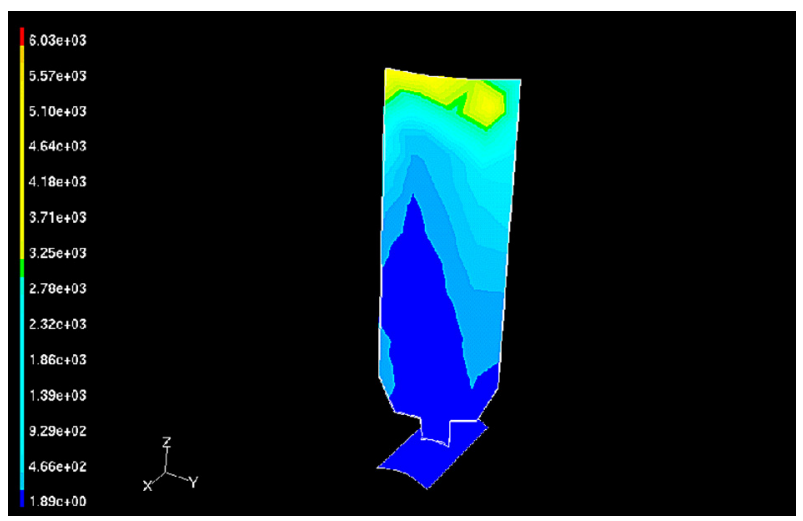

FIGURe 15: Dynamic pressure on the suction side without radiator (unit in Pascal).

It can be seen clearly that the pressure distribution is different on the two sides of the blade partly due to the direction of rotation of the blade.

Figures 14 and 15 show the dynamic pressure on the pressure and suction sides of the blade surface, respectively. The dynamic pressure increases from the hub to the tip on both sides with the maximum pressure occuring close to the tip of the blade. Figure 16 illustrates the dynamic pressure contours on the blade pressure surface and on the surface of the tip shroud. Because the tip shroud is very close to the blade tip with a distance of approximately 0.4 inch, there is pressure interference between the blade and the shroud. Figure 17 is the total pressure on the pressure side and on the top face. By comparison with the previous figures, it can be seen that the dynamic pressure is dominant in the overall pressure distribution. Figure 18 is the velocity vector on the pressure side of the blade. The absolute velocity increases from the hub to the tip, giving rise to increasing dynamic pressure, which is consistent with the pressure contours shown earlier.

\subsection{Axial fan with radiator}

In this section, a radiator is attached to the fan to analyze the changes in the flow pattern. Figures 19 and 20 show

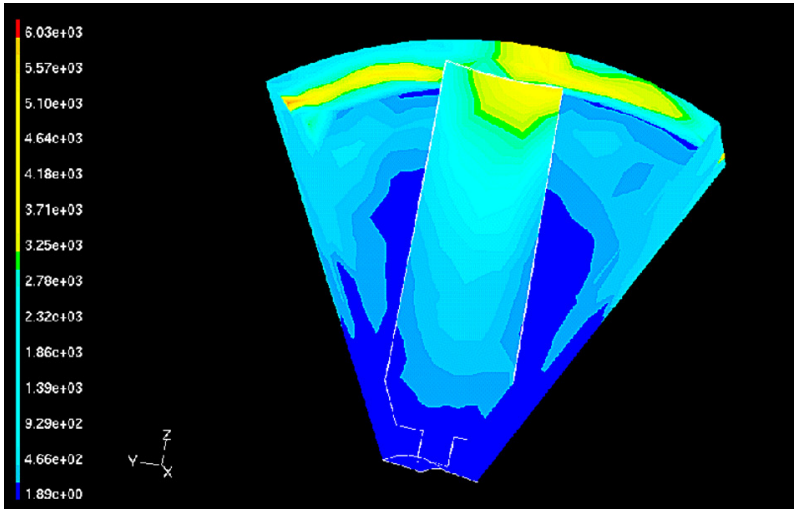

FIGURE 16: Dynamic pressure on the pressure side and top face of the domain without radiator (unit in Pascal).

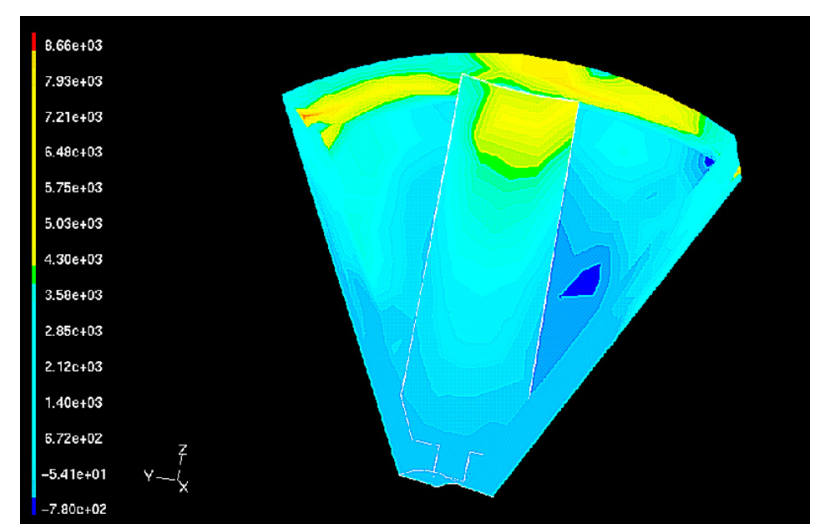

Figure 17: Total pressure on the pressure side and top face of the domain without radiator (unit in Pascal).

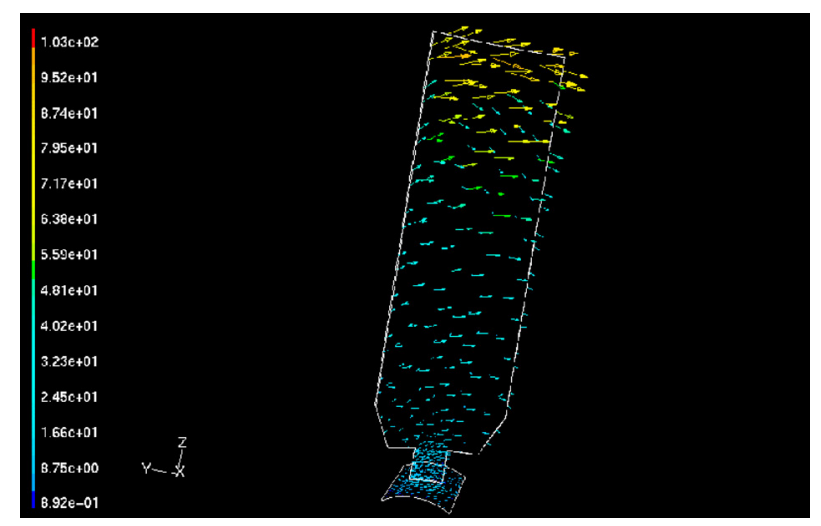

FIGURE 18: Velocity vectors on the pressure side of the domain without radiator (unit in $\mathrm{m} / \mathrm{s}$ ).

the static pressure on the pressure and suction sides of the blade, respectively. Comparing Figures 11 and 19, the magnitude of the pressure has changed, with higher pressure toward the center of the blade on the pressure side. Also shown in Figure 19 is five different locations used to compare the 


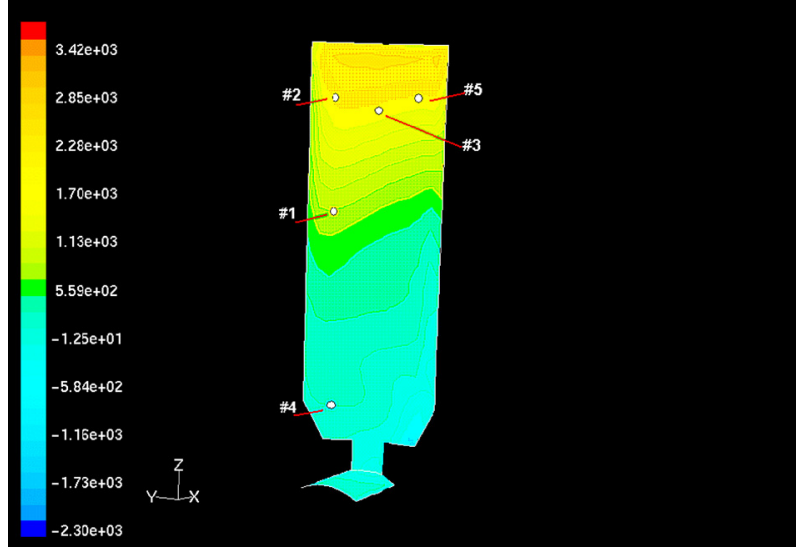

FIgURE 19: Static pressure distribution on pressure side of a fan blade with radiator (unit in Pascal).

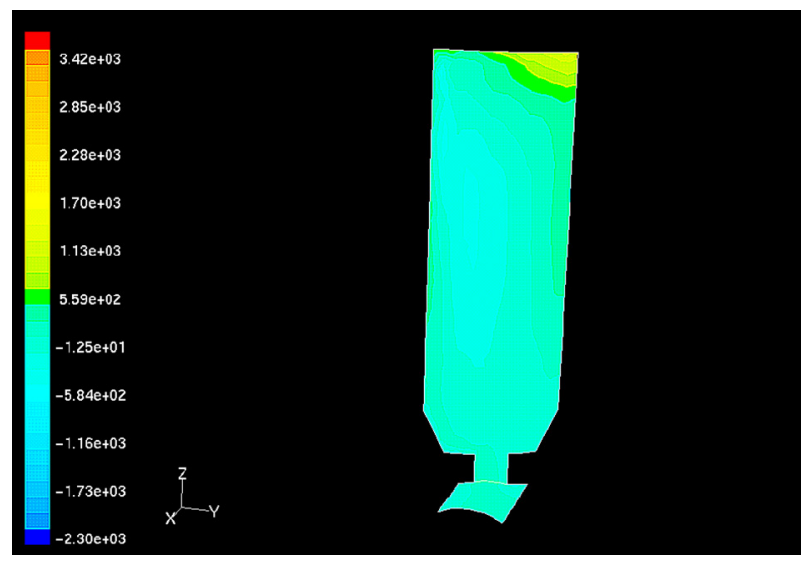

Figure 20: Static pressure distribution on suction side of a fan blade with radiator (unit in Pascal).

TABLE 3: Comparison of static pressure at selected locations.

\begin{tabular}{ccc}
\hline Point no. & Simulation value $(\mathrm{Pa})$ & Measured value $(\mathrm{Pa})$ \\
\hline 1 & 684 & 859 \\
2 & 1850 & 1498 \\
3 & 1800 & 1798 \\
4 & 130 & 240 \\
5 & 1850 & 1298 \\
\hline
\end{tabular}

measured pressure and simulation values. The results are tabulated in Table 3. Although there are some discrepancies between the simulation results and experimental measurement, it can be noticed that the static pressure generally increases from the hub to the tip (point $4 \rightarrow 1 \rightarrow 2$ ) but the pressure changes slightly from the leading side to the trailing side (point $5 \rightarrow 3 \rightarrow 2$ ).

Figure 20 shows that the static pressure is almost uniform on the blade surface with an elevated pressure near the tip of the blade. This is different from what is shown in Figure 12, which has higher pressure around the edges of the blade. The difference in pressure is attributed to the attachment

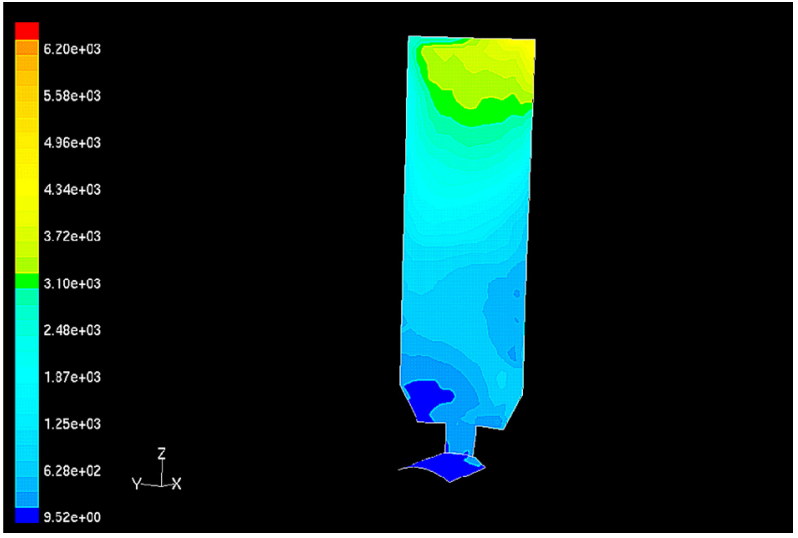

FIgURE 21: Dynamic pressure on the pressure side with radiator (unit in Pascal).

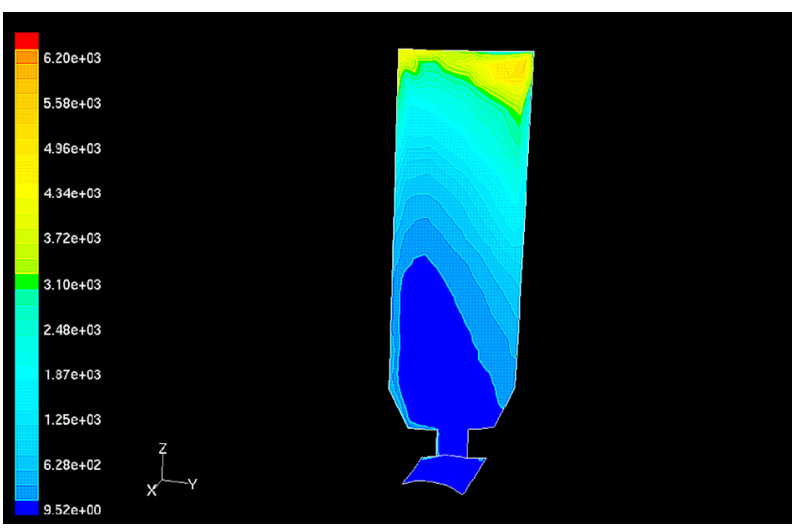

Figure 22: Dynamic pressure on the suction side with radiator (unit in Pascal).

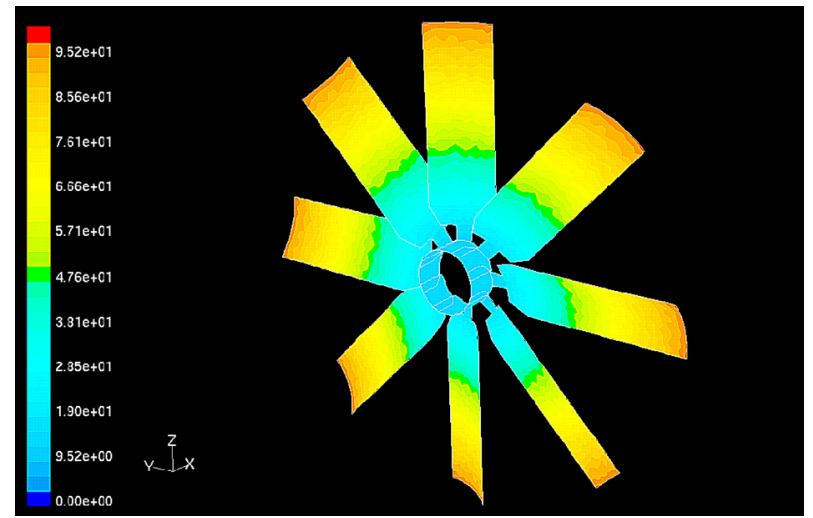

FIGURE 23: Contours of velocity magnitude on the pressure side with radiator (unit in $\mathrm{m} / \mathrm{s}$ ).

of a radiator in front of the axial fan, resulting in a blockage of the flow. Figures 21 and 22 show the dynamic pressure on the pressure and suction sides, respectively. The 


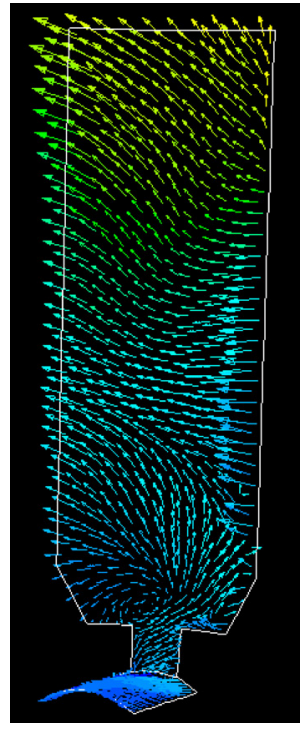

(a)

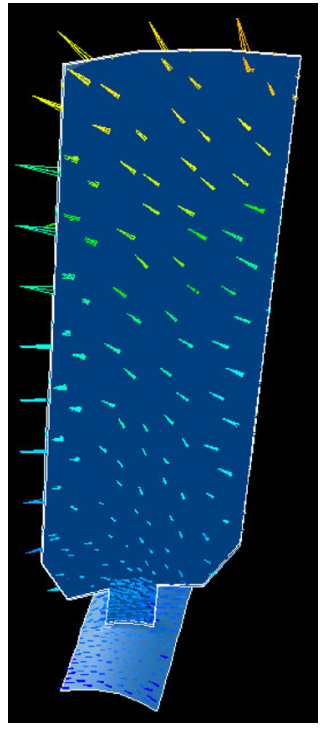

(b)

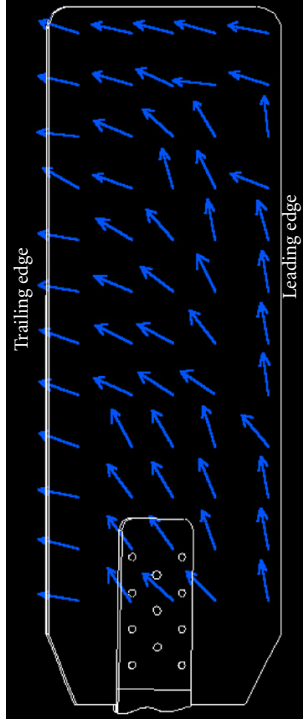

(c)

FIgURE 24: Comparison of CFD simulation and flow visualization technique (tuft method): (a) CFD with radiator; (b) CFD without radiator; and (c) flow visualization without radiator.

maximum pressure occurs near the tip, which is consistent with the case where there is no radiator. Shown in Figure 23 is the velocity contours on the pressure side for the entire axial fan. The velocity increases steadily from the hub to the tip.

Finally, flow visualization is presented for cases with and without a radiator attached to the fan. In Figure 24, a comparison is made between CFD simulation and flow visualization using the tuft method. Figures 24(a) and (b) are the simulated flow patterns and Figure $24(\mathrm{c})$ is the computerized image of the tufts for the case without radiator. Figures 24(b) and (c) show quite similar flow patterns, but Figure 24(c) gives higher tangential velocity near the tip and higher radial velocity at the leading edge.

\section{CONCLUSION}

In this study, the experimental and CFD analyses have been performed to investigate the performance of an industrial axial fan. In order to design more efficient fans that provide uniform airflow while consuming less power, a better understanding of axial fan blade airflow and the resulting stresses in the fan blade are needed. From the results presented in this paper, several conclusions can be drawn.

(1) Experimental measurement and CFD simulation of the performance of an axial fan have been carried out. The experimental part includes the measurement of the velocity profile, the measurement of the stress and strain on the fan blade, and flow visualization. CFD simulation is done by using unstructured mesh generation coupled with rotating reference frame to predict the flow field and pressure distributions on the blades.
(2) The difference in the flow and pressure generated by the addition of a radiator in front of the axial fan is studied.

(3) The addition of a radiator to the axial fan hinders the inflow and changes the flow pattern. It also produces approximately 10-20\% stresses (from measurement) and forces (from simulation) on the blade surface.

(4) Maximum stresses occurred in the area of strain gages no. 2 and no. 3 both with and without radiator on the front and back of the fan. Thus, these locations are most likely to fail over an extended period of time.

(5) Simulation results show that the addition of a radiator causes an increase in the maximum static pressure at the tip of the blade, and the pressure increases about $10-20 \%$.

(6) The flow visualization technique verifies the results predicted by simulation.

The results presented in this paper can be used as a guideline for future study of rotating machinery.

\section{REFERENCES}

[1] G. N. Abramovich, The Theory of Turbulent Jets, MIT Press, Cambridge, Mass, USA, 1963.

[2] K. R. Mutama and A. E. Hall, "The experimental investigation of jet fan aerodynamics using wind tunnel modeling," Journal of Fluids Engineering, vol. 118, no. 2, pp. 322-327, 1996.

[3] S. A. Huyer, D. Simms, and M. C. Robinson, "Unsteady aerodynamics associated with a horizontal-axis wind turbine," AIAA Journal, vol. 34, no. 7, pp. 1410-1419, 1996.

[4] K. A. Kaupert and T. Staubli, "The unsteady pressure field in a high specific speed centrifugal pump impeller-part 2: transient hysteresis in the characteristic," Journal of Fluids Engineering, vol. 121, no. 3, pp. 627-632, 1999. 

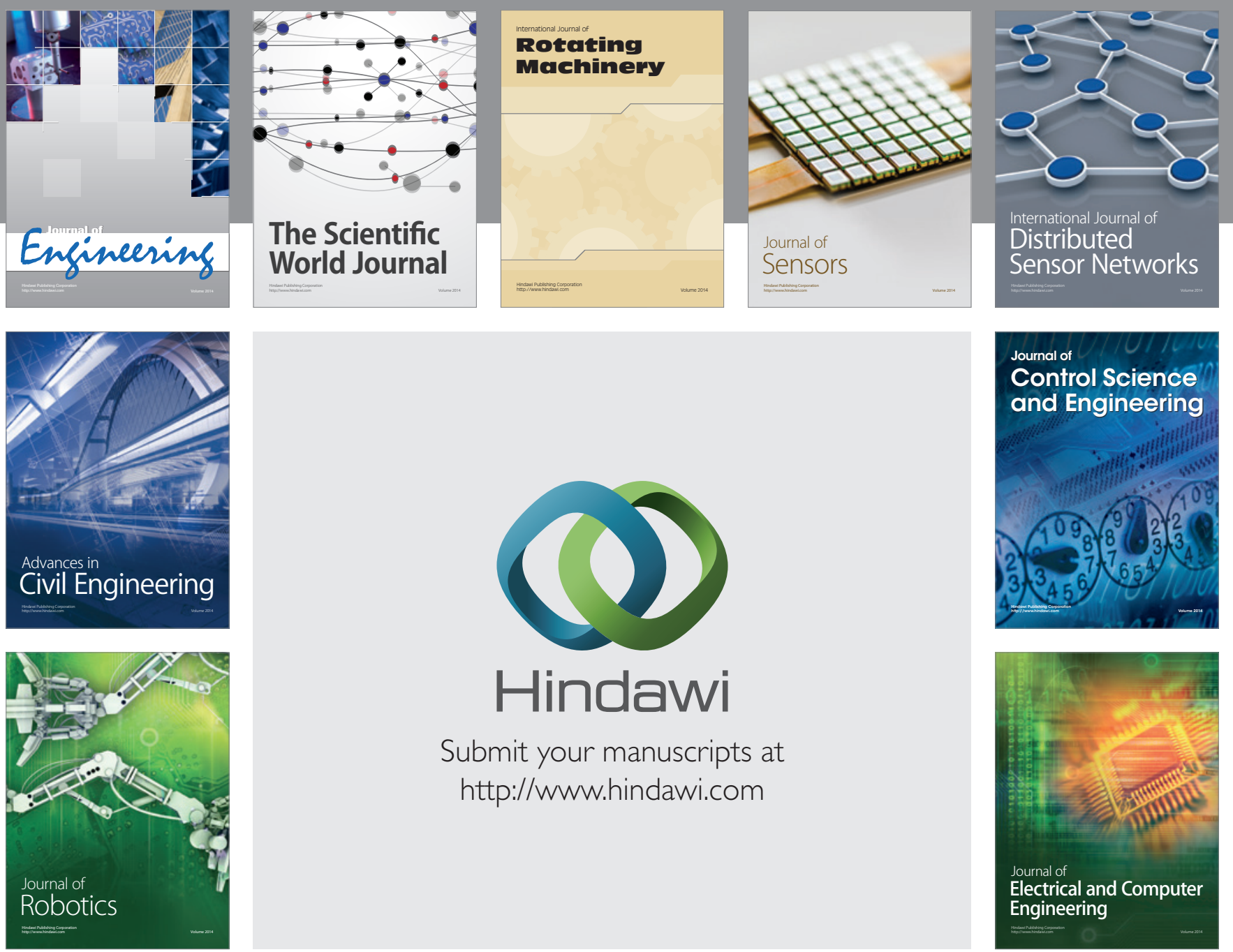

Submit your manuscripts at

http://www.hindawi.com
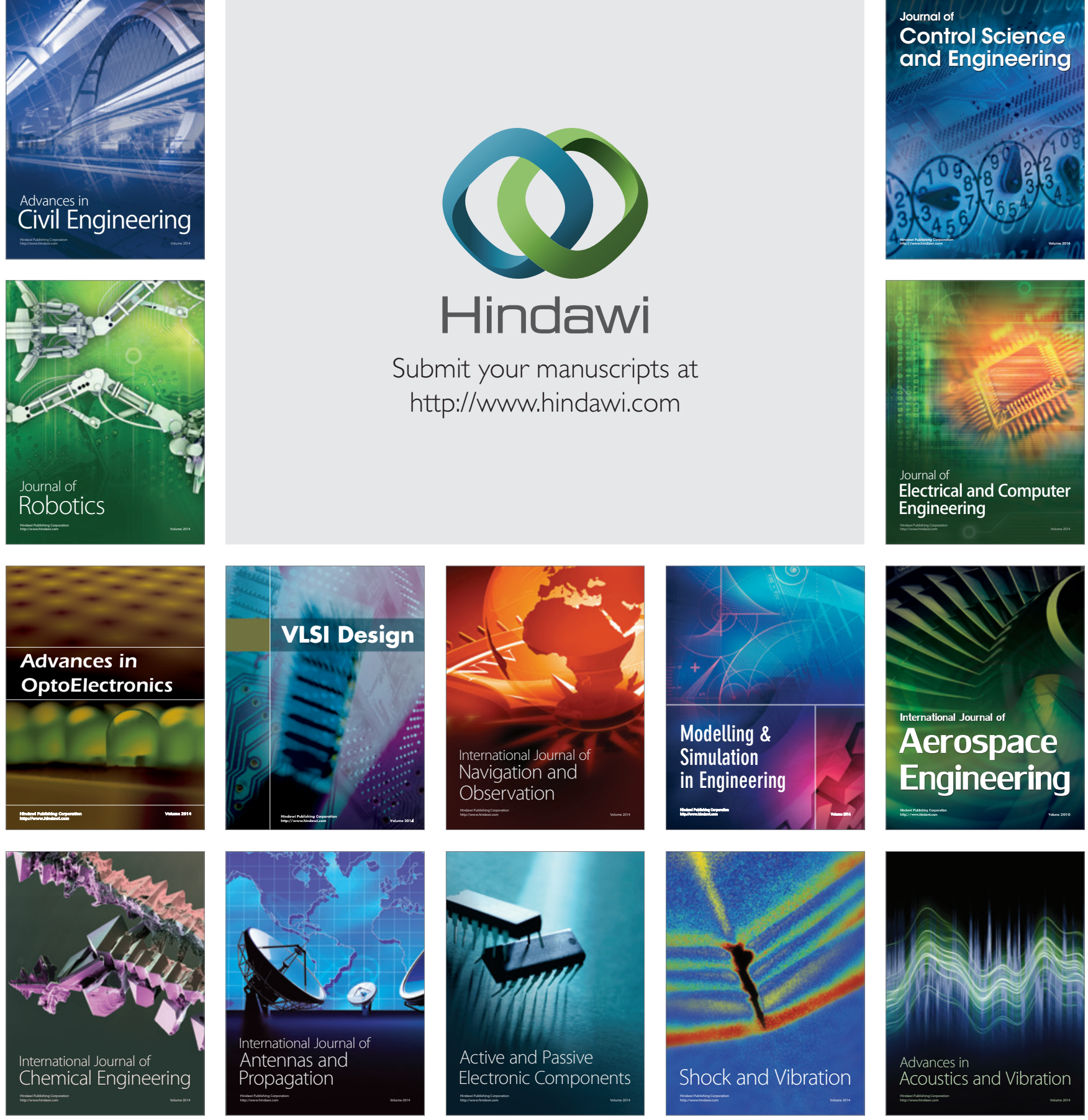